Supplementary Information for:

\title{
An unusually rapid protein backbone modification stabilizes the essential bacterial enzyme MurA
}

Tianze Zhang, Kjetil Hansen, Argyris Politis, Manuel M. Müller*

King's College London, Department of Chemistry, 7 Trinity Street, London SE1 1DB, United Kingdom

*To whom correspondence should be addressed; email: manuel.muller@kcl.ac.uk

Supplementary Figures 1-15

Supplementary Materials and Methods

Supplementary References 


\section{SUPPLEMENTARY FIGURES}

a
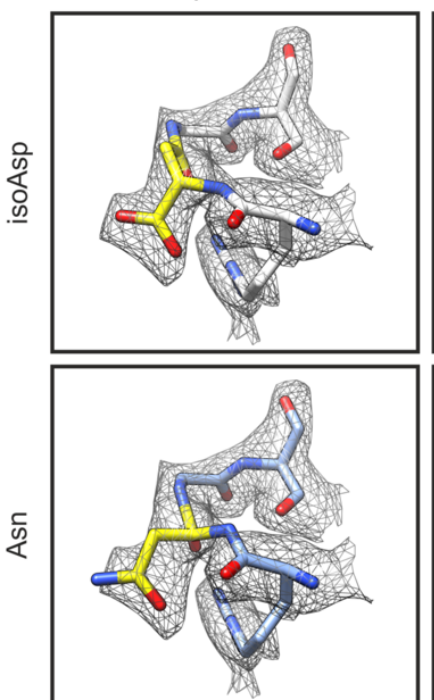

b

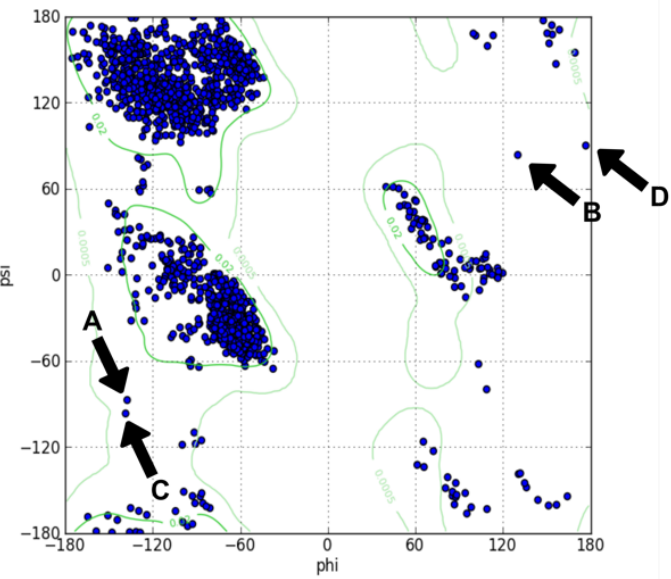

3vcy: Chain B
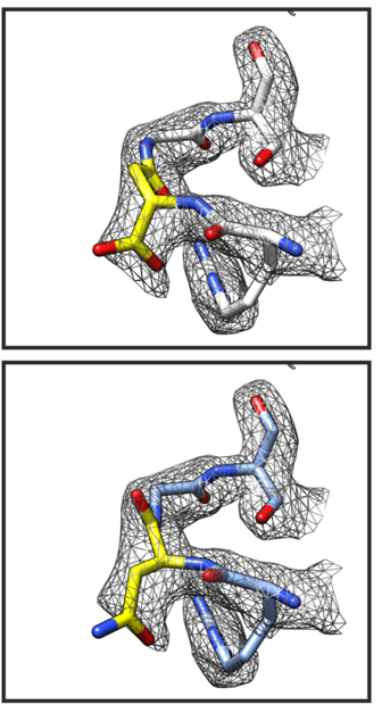

c
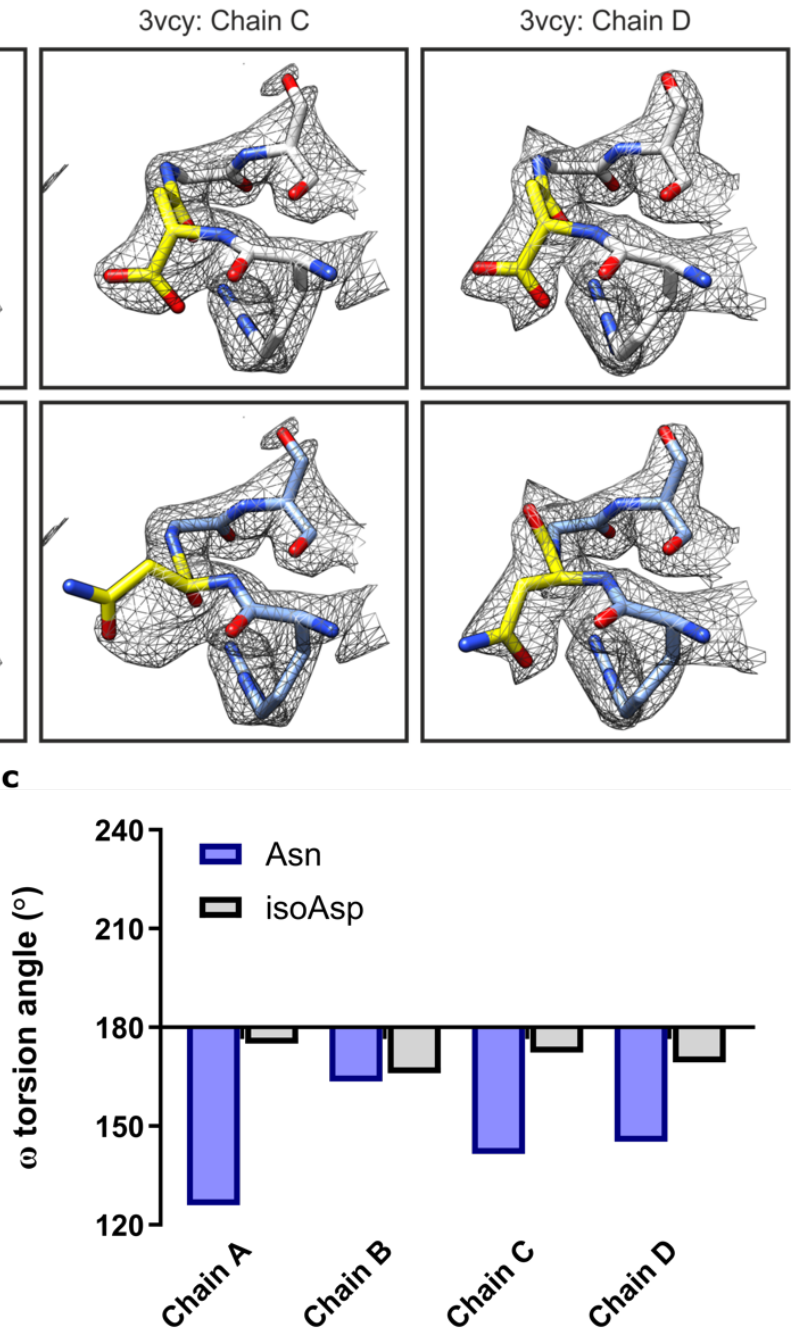

Figure S1: The crystal structure of MurA from Vibrio fischeri features an isoAsp residue. a The electron density of MurA from $V$. fischeri accommodates an isoAsp residue. The structure of 3vcy was re-refined with isoAsp68 (top) and compared to the original structure with Asn68 (bottom). All four chains of the asymmetric unit are shown. Improved fits with isoAsp are observed for chains A-C. b Ramachandran analysis of MurA from Vibrio fischeri (PDB code: $3 v_{c y}{ }^{\text {; }}$ generated with UCSF Chimera $^{2}$ ). Asn68 (indicated with arrows; four monomers per asymmetric unit) adopts unfavourable $\varphi$ and $\psi$ angles, further suggesting that these sites have isomerized to isoAsp. c The $\omega$-torsion angles of the amide bond connecting Arg67-Asn68 deviate from the planar trans arrangement expected for polypeptides in chains $A, C$ and $D$. 


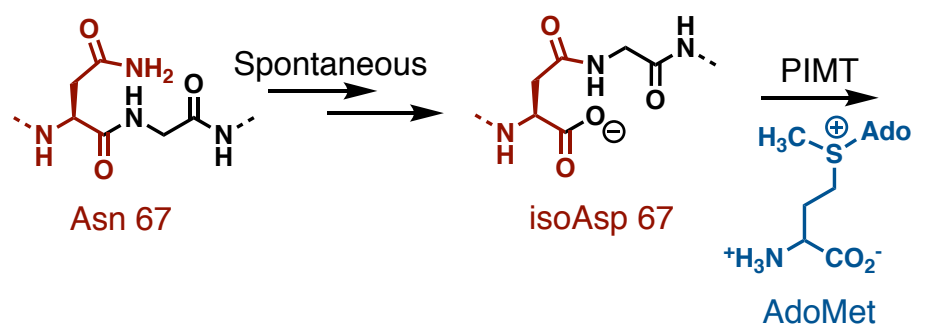

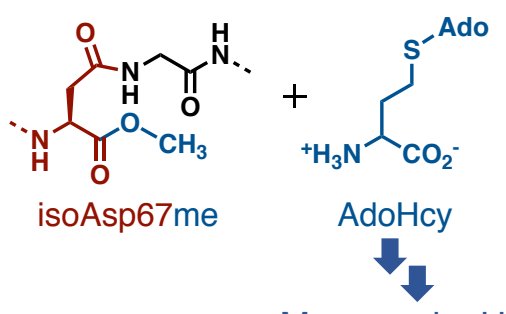

Measure by HPLC

AdoHcy standard curve

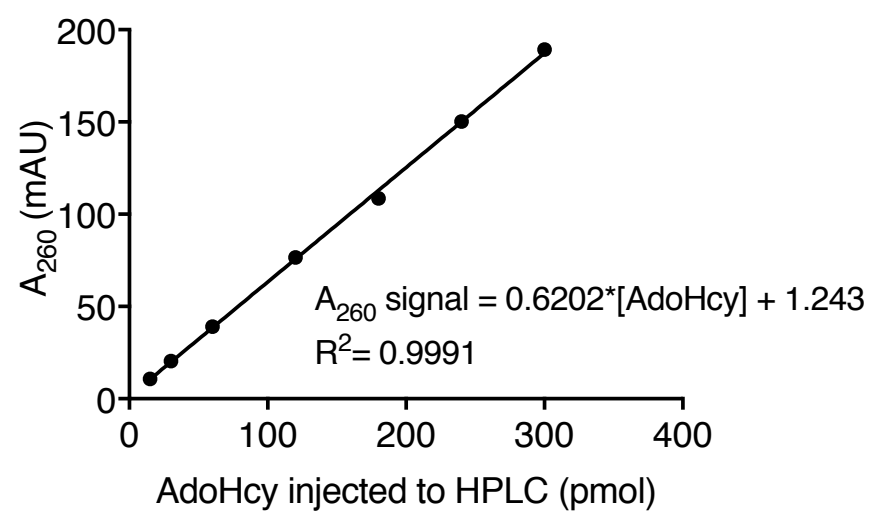

Figure S2: Calibration curve for quantification of AdoHcy by reverse-phase HPLC. $60 \mu \mathrm{L}$ 0.25-5 $\mu \mathrm{M}$ AdoHcy samples were injected to HPLC Agilent Zorbax 300SB-C18 column and run with a linear gradient of 0 to $30 \%$ acetonitrile $\left(0.1 \%\right.$ TFA) in water $\left(0.1 \%\right.$ TFA). $A_{260}$ signal integration versus AdoHcy injected (pmol) was plotted. A schematic for the isoAsp quantification assay is shown on top. 


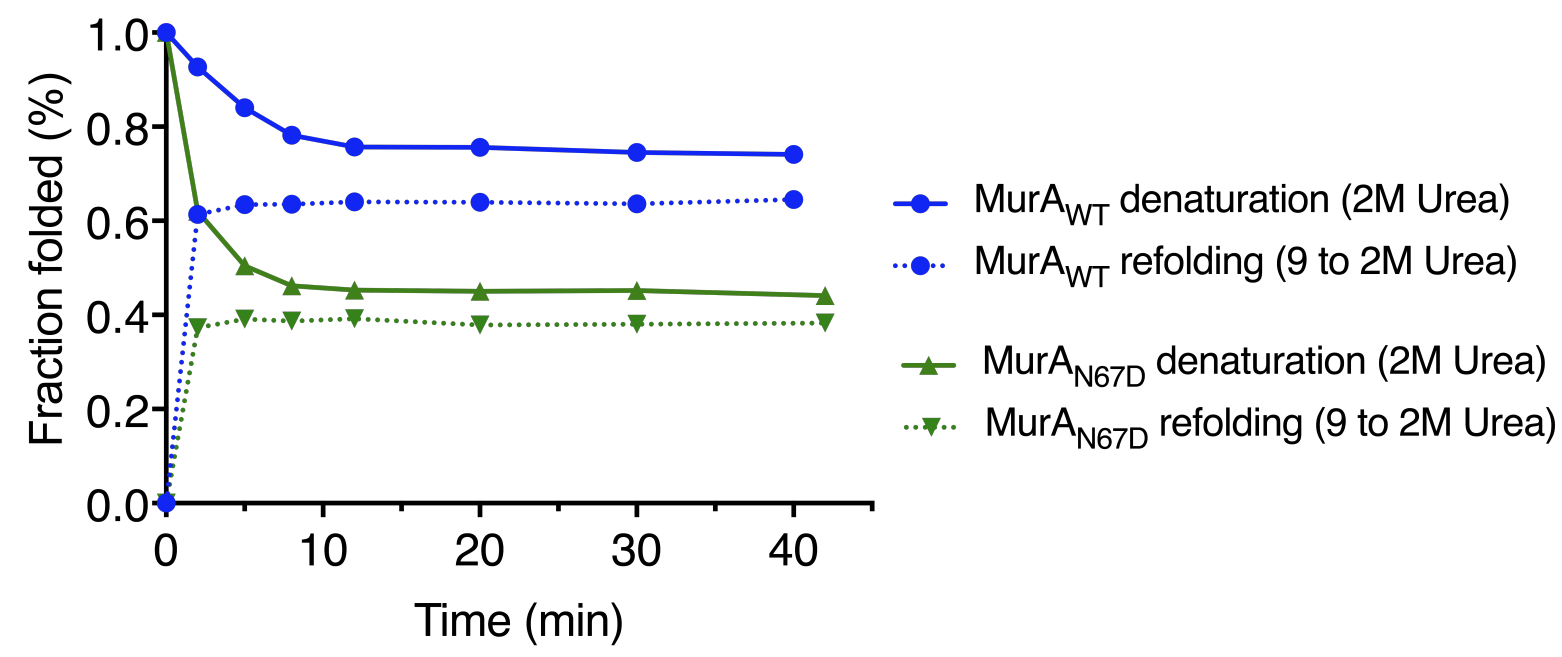

Figure S3: Chemical denaturation and refolding kinetics for MurA $\mathrm{WT}_{\mathrm{WT}}$ and MurA $\mathrm{N}_{\mathrm{N67D}}$. For denaturation, both proteins were diluted to a final concentration of $2 \mathrm{M}$ urea in $3 \mathrm{~mL}$ and the circular dichroism signal at $222 \mathrm{~nm}$ was measured over the course of $40 \mathrm{~min}$ at $25^{\circ} \mathrm{C}$. For the refolding kinetics, both proteins were incubated in $9 \mathrm{M}$ urea buffer $(300 \mu \mathrm{L})$ for $15 \mathrm{~min}$ at $25^{\circ} \mathrm{C}$ and were rapidly diluted with native buffer to a final concentration of $2 \mathrm{M}$ urea in a total of $3 \mathrm{~mL}$. The circular dichroism signal was measured over the course of $40 \min 25^{\circ} \mathrm{C}$; the protein final concentration was $0.3 \mu \mathrm{M}$. The $C D$ signal for the unfolding and refolding gradually converged for both MurA $A_{W T}$ and MurA $A_{N 67 D}$. By 40 min, both proteins exhibited a denaturation reversibility of $>85 \%$. 


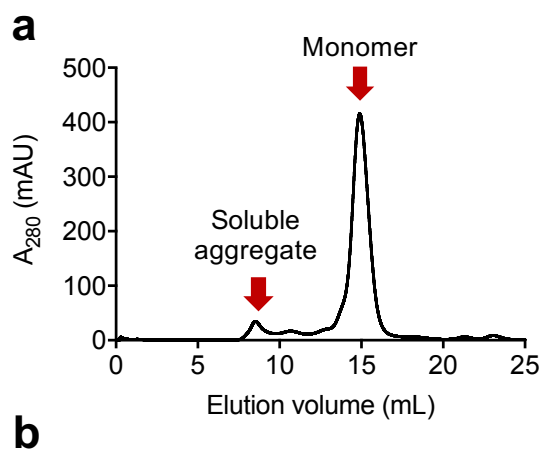

b

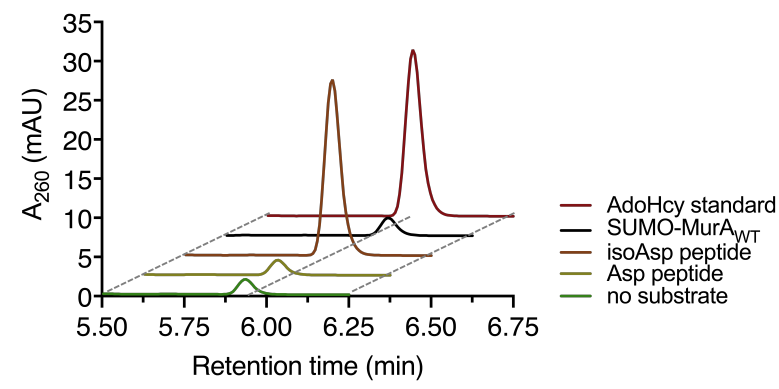

C

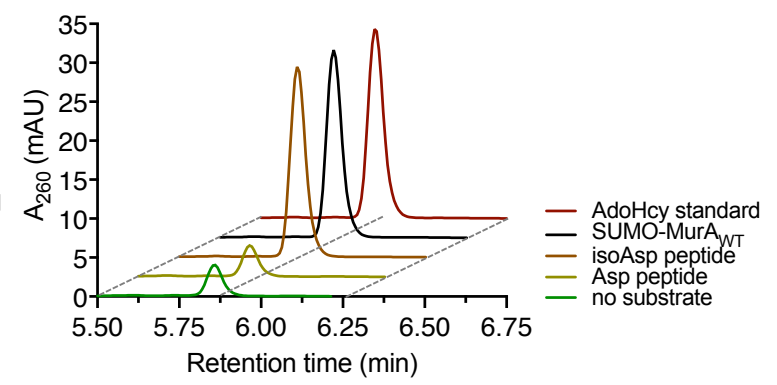

Figure S4: Purification and isoAsp content measurement of SUMO-MurA $A_{W T}$. a Size-exclusion chromatogram of SUMO-MurAwT. A Superdex 200 10/300 column was used for the purification. Monomeric MurA elutes at $14.9 \mathrm{~mL}$, soluble aggregates elute earlier than $10 \mathrm{~mL}$. b,c Quantification of isoAsp content via PIMT-dependant methylation. HPLC traces to quantify AdoHcy formed during the reaction with $0.73 \mu \mathrm{M}$ PIMT under native conditions (b) and 14.6 $\mu \mathrm{M}$ PIMT under partially denaturing conditions (c) are shown. The higher concentration of PIMT in $\mathbf{c}$ was chosen to compensate for potential loss in PIMT activity under partially denaturing conditions. Some chromatogram curves are nudged for better clarity as indicated by dashed lines. 


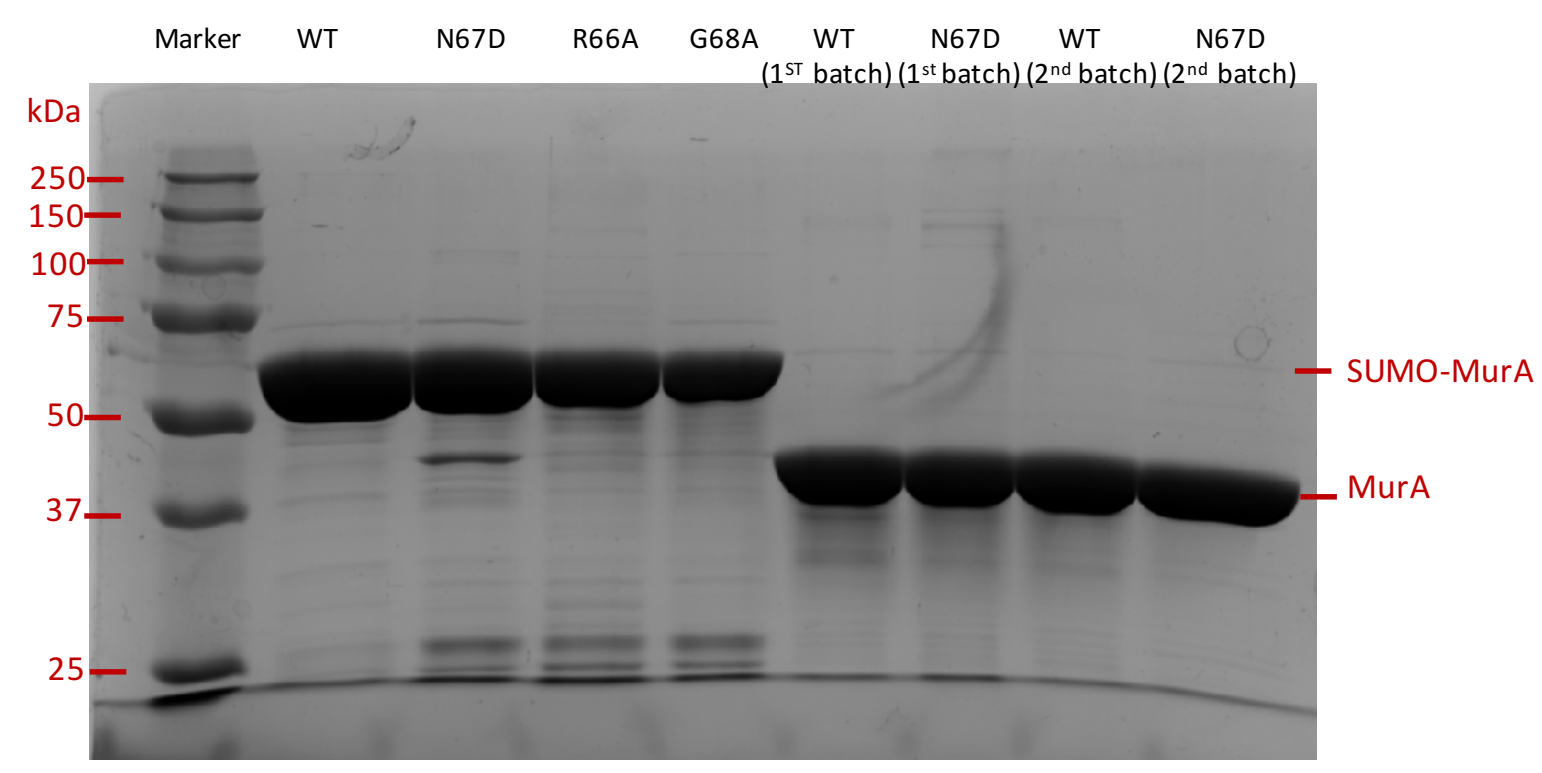

Figure S5: SDS-PAGE analysis of purified proteins used in this study. 
Item name: 190516_TZ190515_1

Channel name: 1: Average Time 3.1944 min : TOF MS (500-3000) ESI+ : Combined

Item description: TZ190515_1 1uM into buffer A

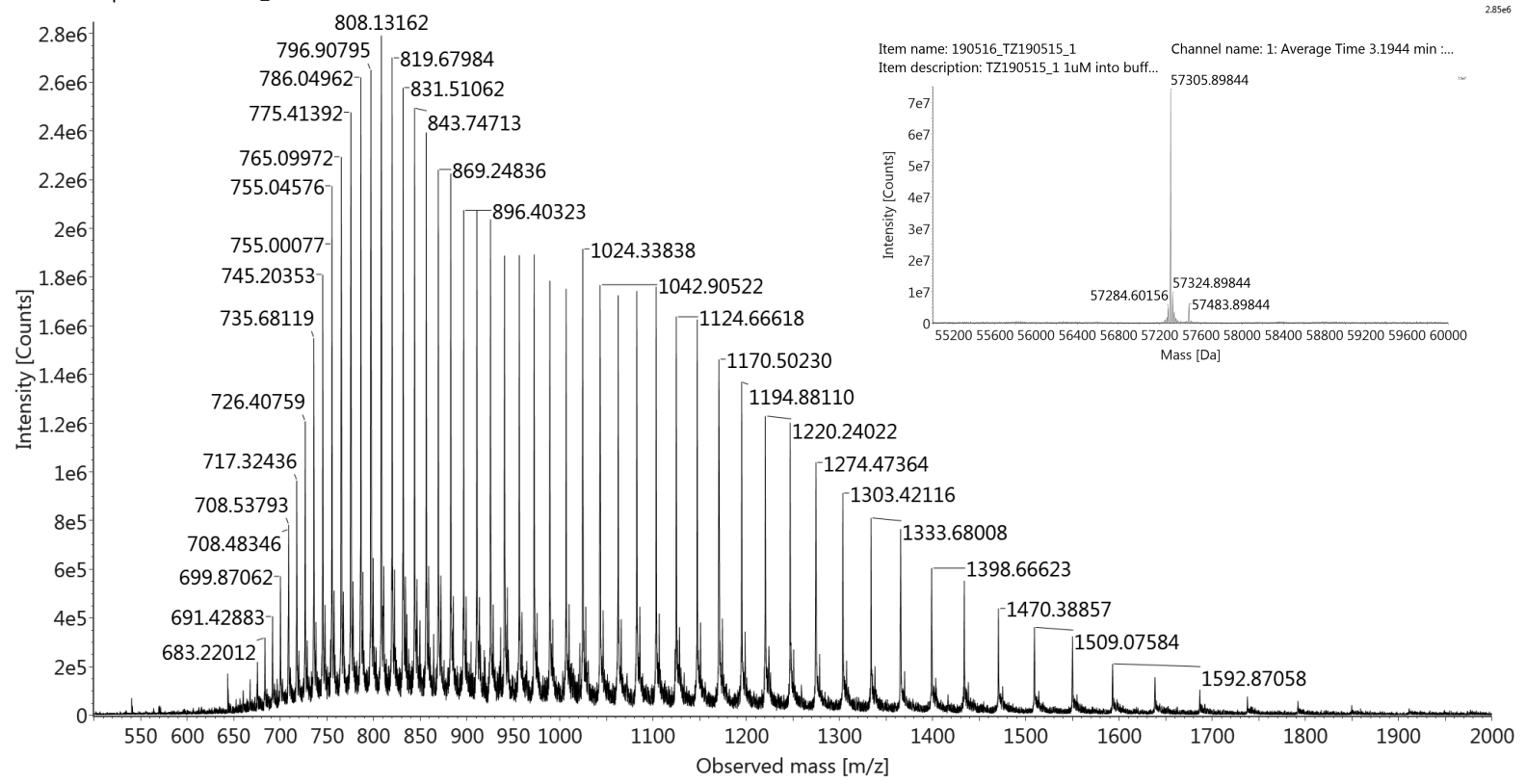

Figure S6a: Deconvoluted spectrum of SUMO-MurA $\mathrm{WT}_{\mathrm{WT}}$ Calculated mass: $57306.47 \mathrm{Da}$ (Asn67isoAsp). Deconvoluted mass: 57305.90 Da.

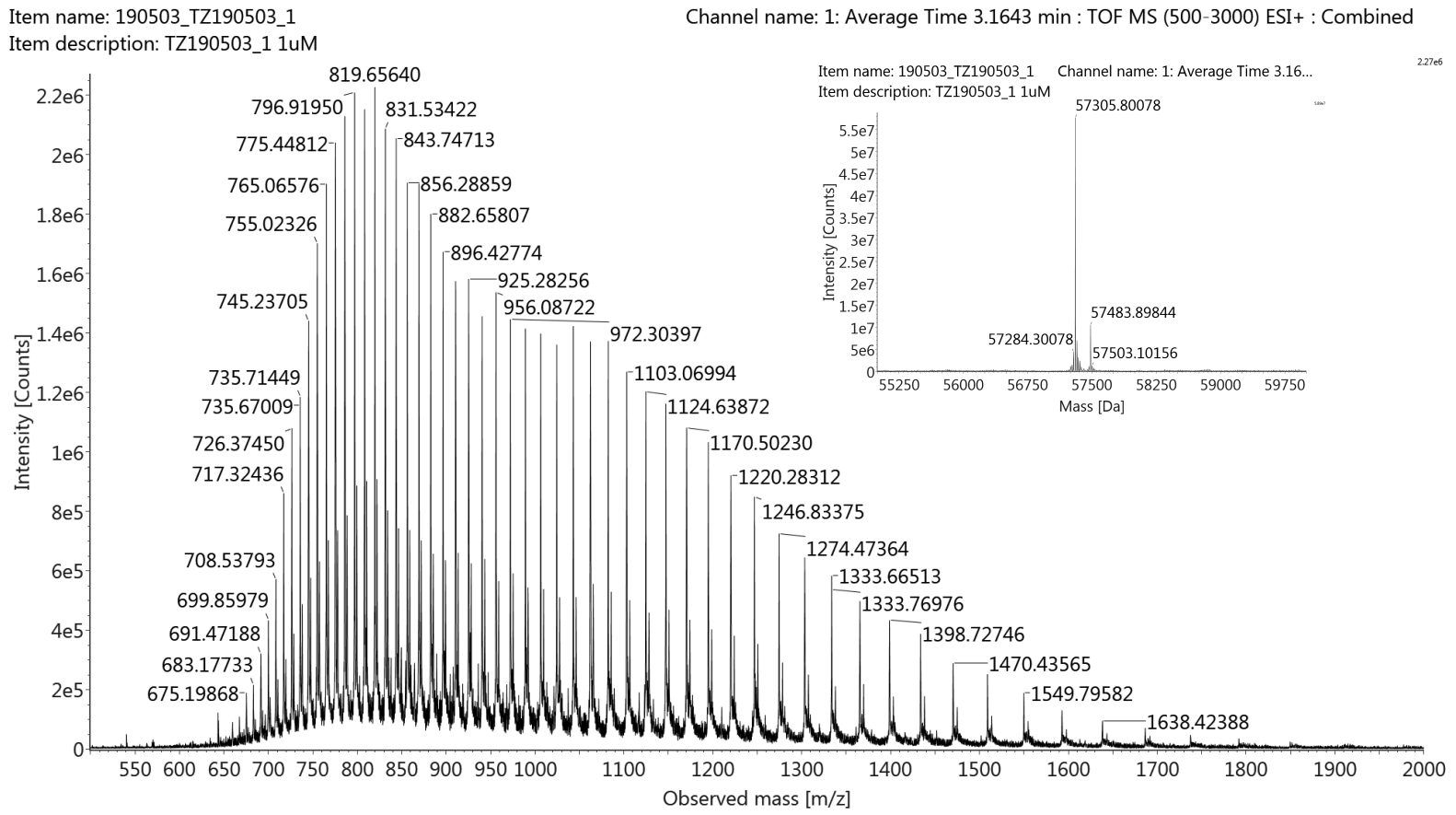

Figure S6b: Deconvoluted spectrum of His-SUMO-MurA ${ }_{\text {N67D }}$. Calculated mass: $57306.47 \mathrm{Da}$.

Deconvoluted mass: $57305.80 \mathrm{Da}$. 


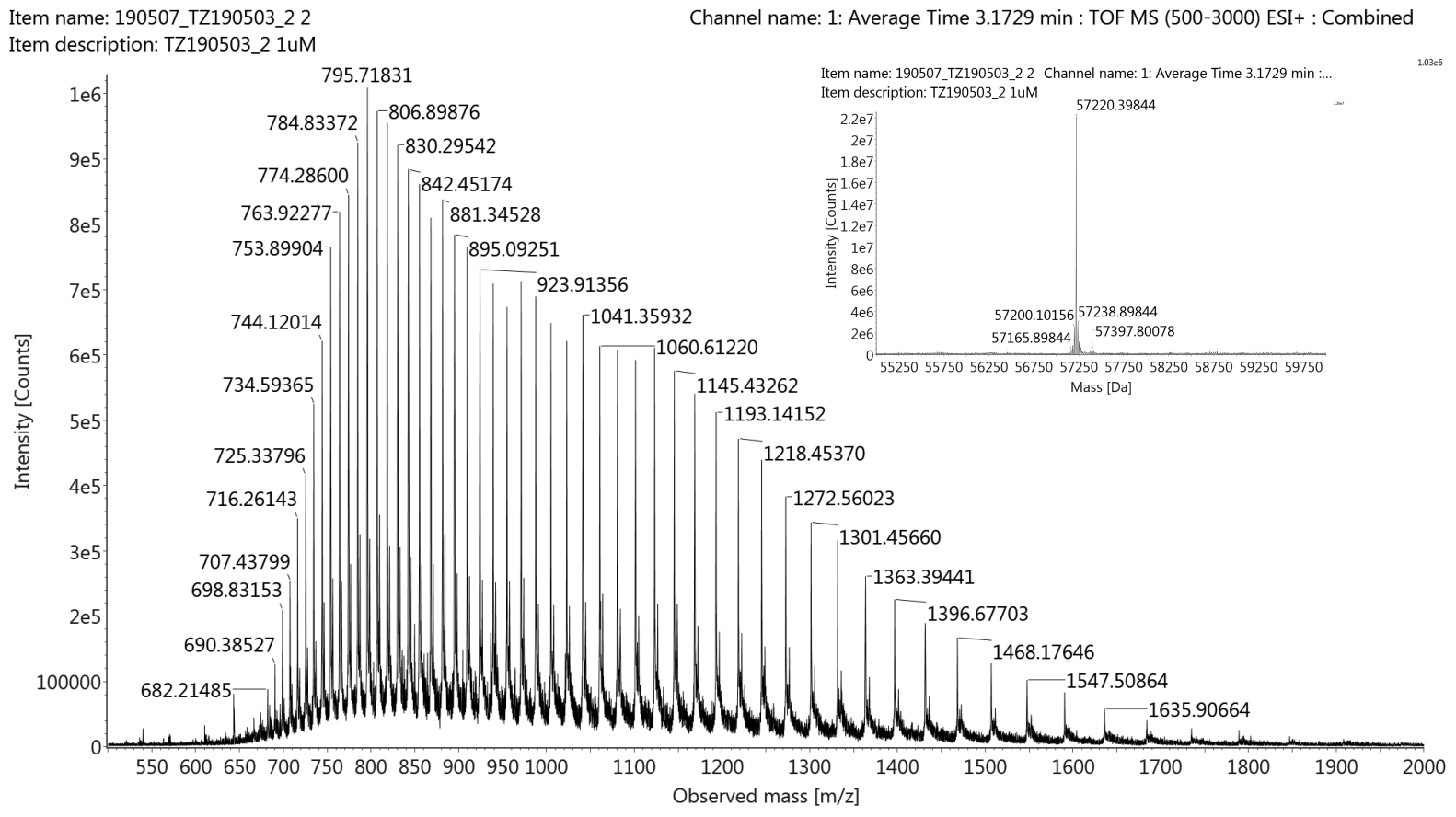

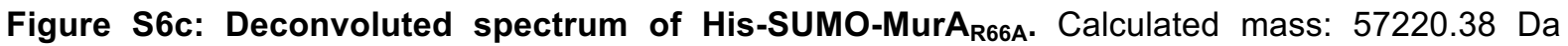
(without deamidation). Deconvoluted mass: 57220.40 Da.

Item name: 190412_TZ190409_2

Item description: TZ190409_2 0.5uM

Channel name: 1: Average Time 3.1986 min : TOF MS (500-3000) ESI+ : Combined

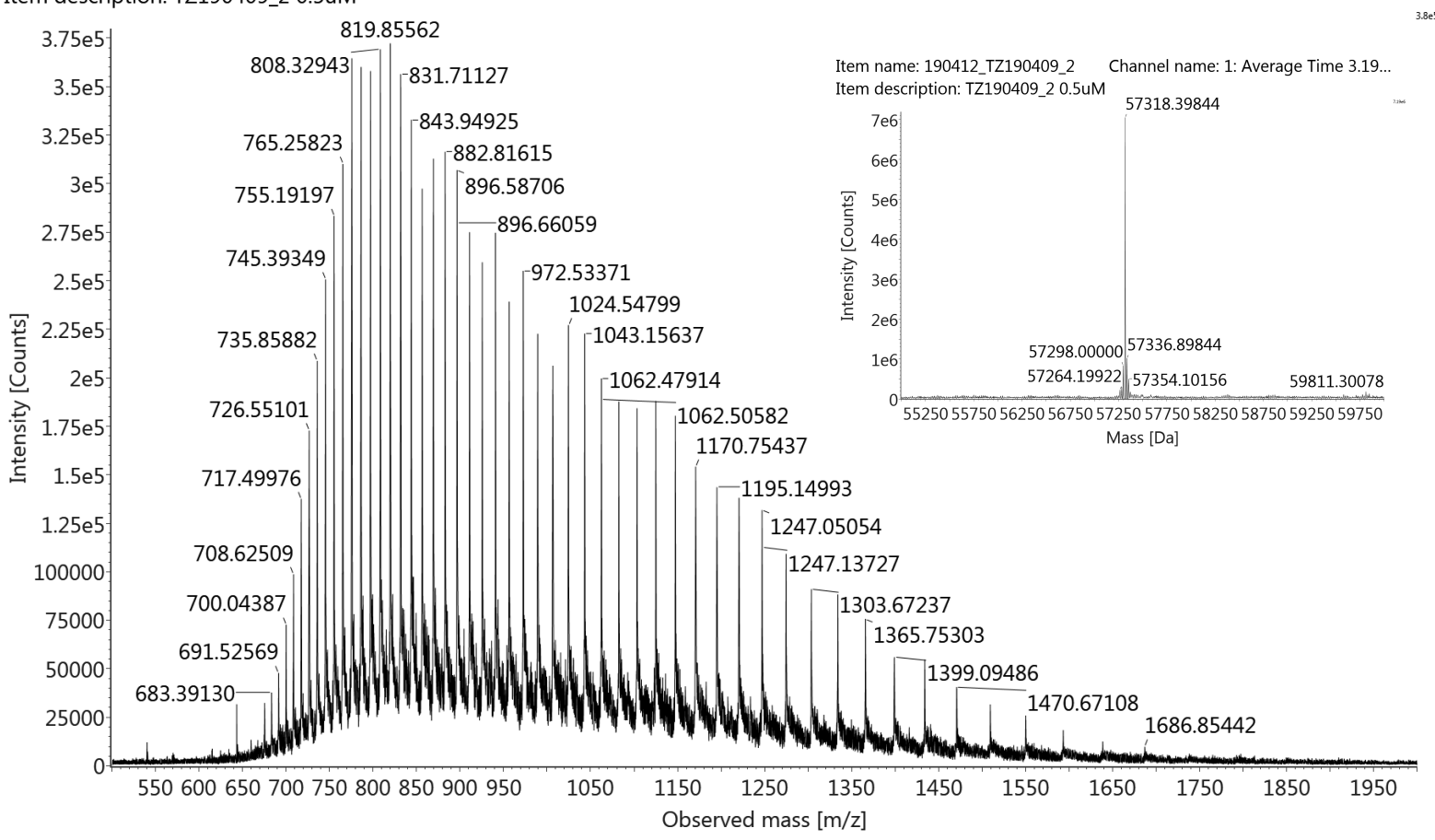

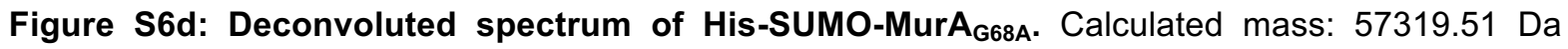
(without deamidation). Deconvoluted mass: $57318.40 \mathrm{Da}$. 
a

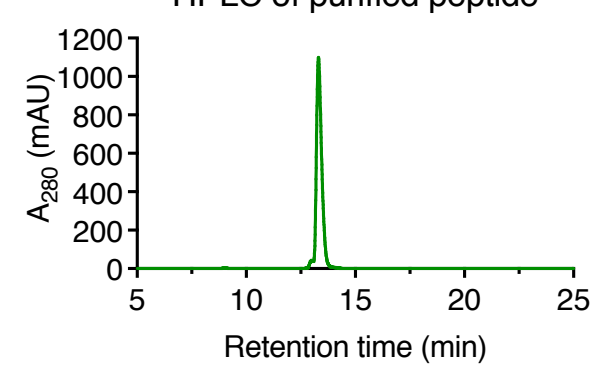

b Synthetic MurA hairpin peptide

(with Asn 67)

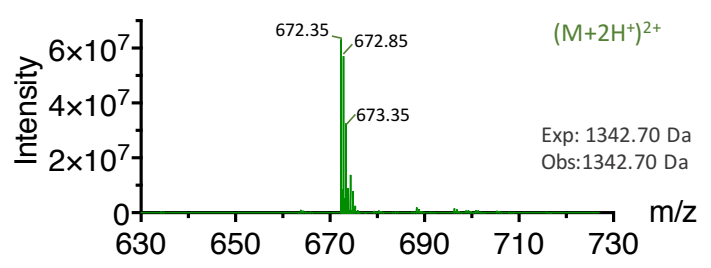

C

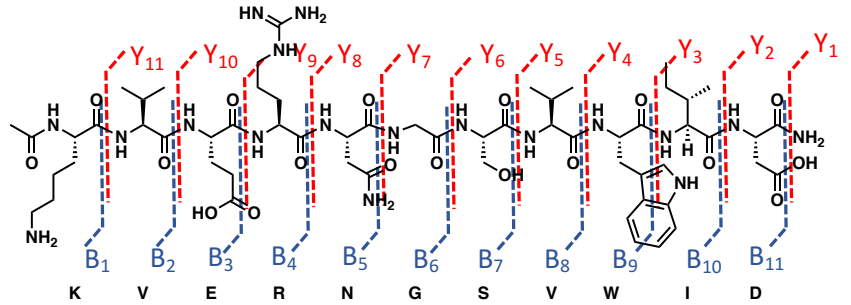

Item name: 190227_TZ190222_LCMSE_3 Item description: $T Z 1902220.01 \mathrm{mg} / \mathrm{ml}$ LCMSE

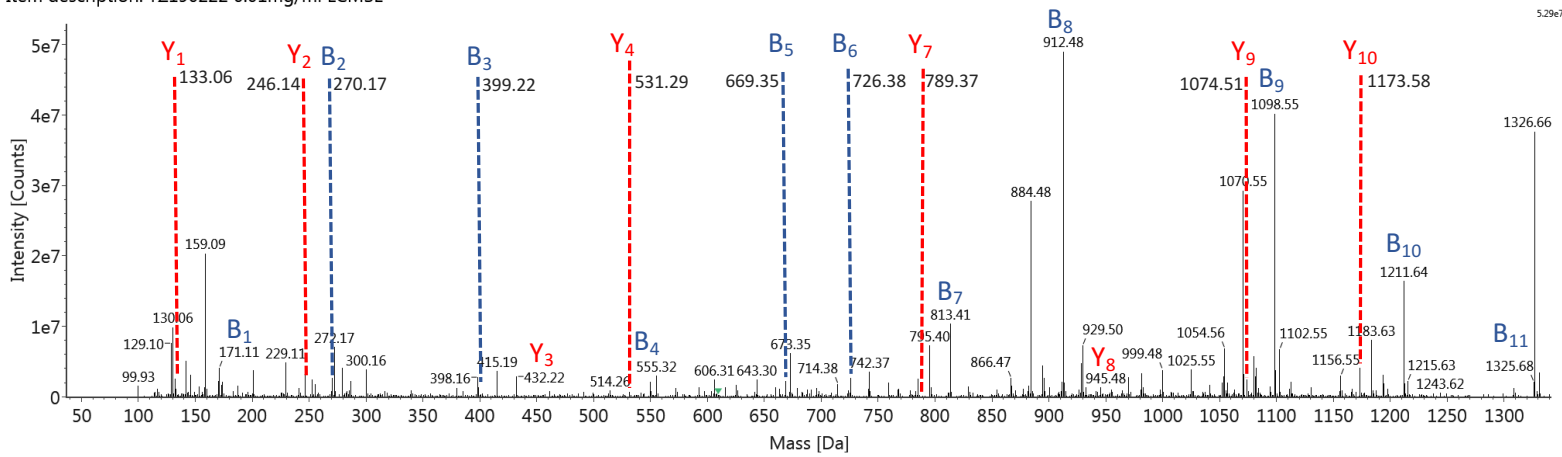

\section{d}

Item name: $190426 \_$TZ190423 MSMS Item description: TZ190423 1.25uM

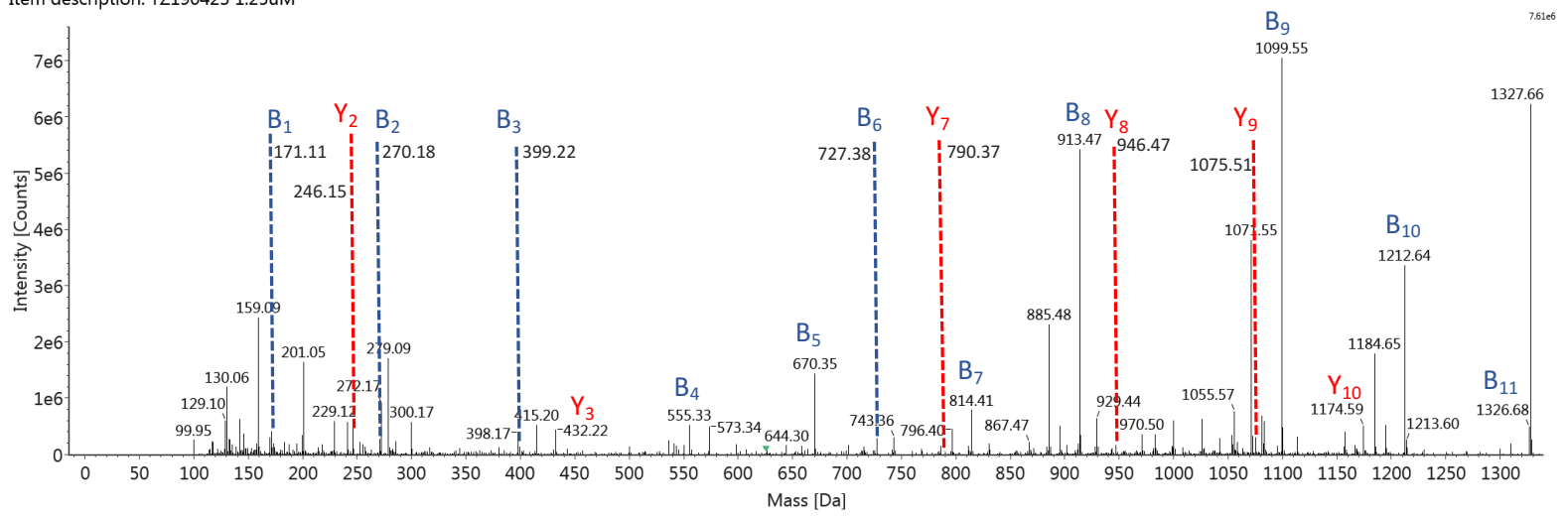

Figure S7: MurA Asn67-containing hairpin peptide characterization and deamidation. a The purity of Fmoc-SPPS synthesized 11-amino-acid-peptide (residue 63-73) in MurA was tested by analytical C18 column with a gradient of $0-70 \% \mathrm{~B}$ at $50{ }^{\circ} \mathrm{C}$. $\mathbf{b}$ LC-MS analysis of the synthetic peptide (Expected: 1342.70 Da; observed: $1342.70 \mathrm{Da}$ ). c MS/MS spectrum of the intact peptide. $\mathbf{d}$ The MS/MS spectrum of the deamidated peptide confirms a 1Da change at position 67, consistent with an Asn67Asp/isoAsp. 


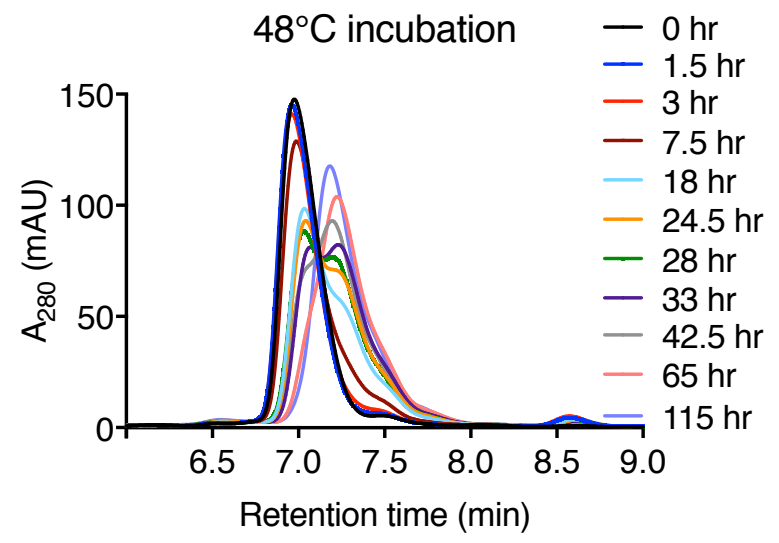

$65^{\circ} \mathrm{C}$ incubation

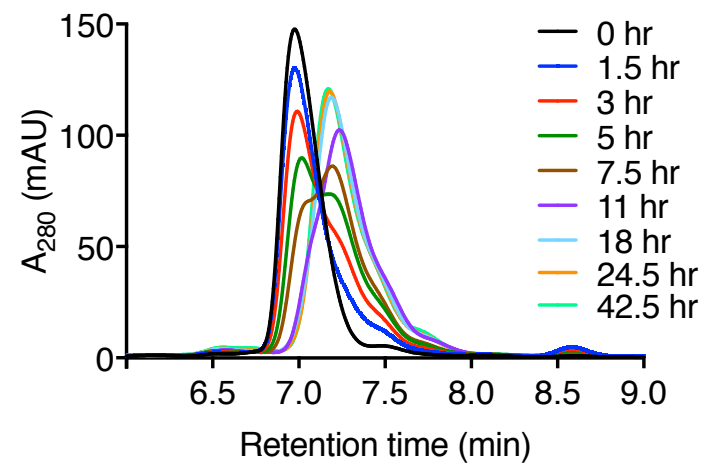

$55^{\circ} \mathrm{C}$ incubation

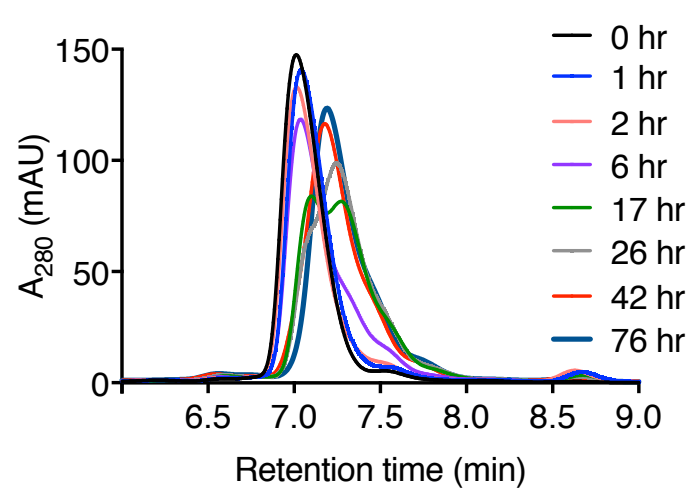

$75^{\circ} \mathrm{C}$ incubation

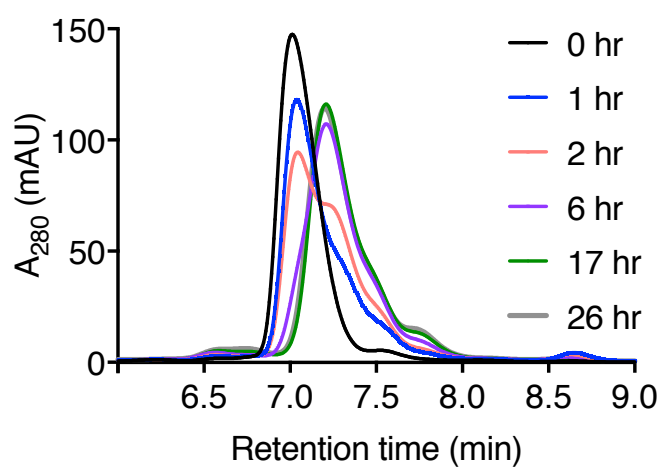

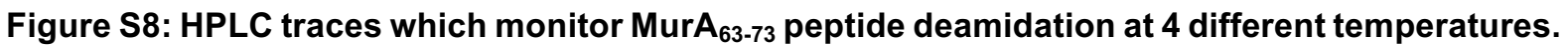
Asn67 $63-73$ peak (retention time $7.0 \mathrm{~min}$ ) decreases while (iso)Asp67 $63-73$ peak (retention time $7.2 \mathrm{~min}$ ) increases with time. 
a

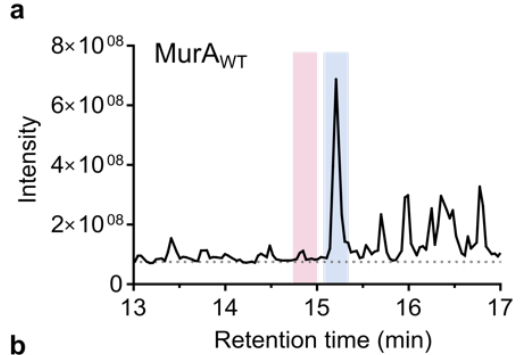

b

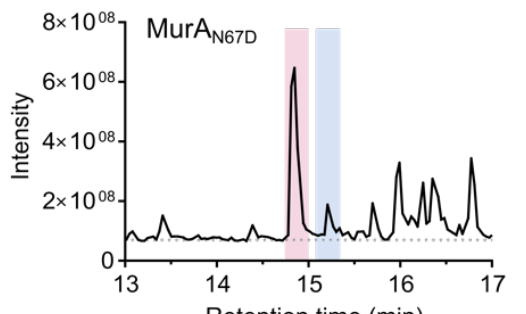

c

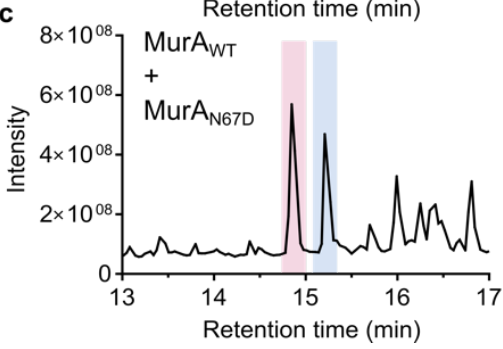

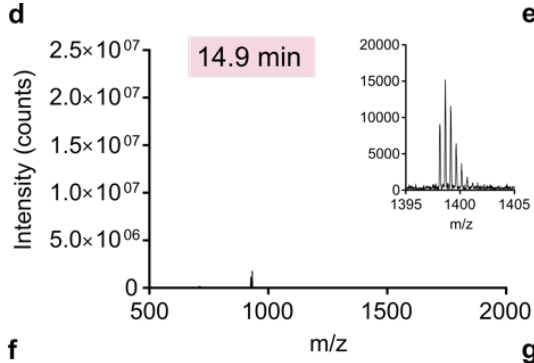

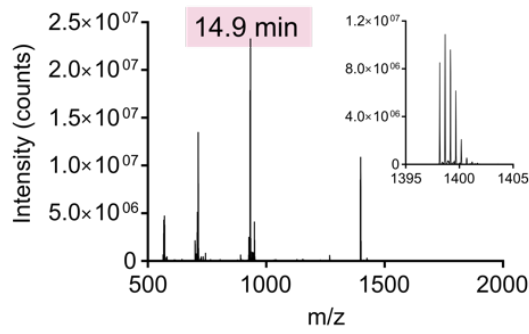

64-VERXGSVWIDASNVNNFSAPYDLVK-88 Calc: $2794.36 \mathrm{Da} ;[\mathrm{M}+2 \mathrm{H}]^{2+}=1398.19$

Figure S9: Peptide mapping with LysC confirms the modification state of residue 67 in MurA variants. LC-MS analysis of LysC-digested MurA $\mathrm{WT}_{\mathrm{T}}(\mathbf{a})$ and $\mathrm{MurA}_{\mathrm{N67D}}(\mathbf{b})$. Peaks corresponding to peptide 64-88 (VERXGSVWIDASNVNNFSAPYDLVK) elute at $14.9 \mathrm{~min}(\mathrm{red}, \mathrm{X}=\mathrm{Asp}$ ) and $15.2 \mathrm{~min}$ (blue, $\mathrm{X}=$ isoAsp). The total ion count is plotted on the $\mathrm{Y}$-axis. $\mathbf{c}$ Co-injection of the digestion reactions proves that the major species encompassing residue 67 of MurA $A_{W T}$ and MurA $A_{N 67 D}$ are chemically distinct. Mass spectra of the 14.9 and 15.2 min peaks for $\operatorname{MurA}_{W T}(\mathbf{d}, \mathbf{e})$ and $\operatorname{MurA}_{\mathrm{NG7D}}(\mathbf{f}, \mathbf{g})$ are shown. Insets depict zoom-ins of the $[\mathrm{M}+2 \mathrm{H}]^{2+}$ peak. Estimates based on the chromatogram and mass spectra intensity suggest that MurA $A_{W T}$ has $>90 \%$ of isoAsp $(\mathbf{a}, \mathbf{d}, \mathbf{e})$ while $\operatorname{Mur}_{N 67 D}(\mathbf{b}, \mathbf{f}, \mathbf{g})$ contains predominantly Asp with approximately $10 \%$ isoAsp. 

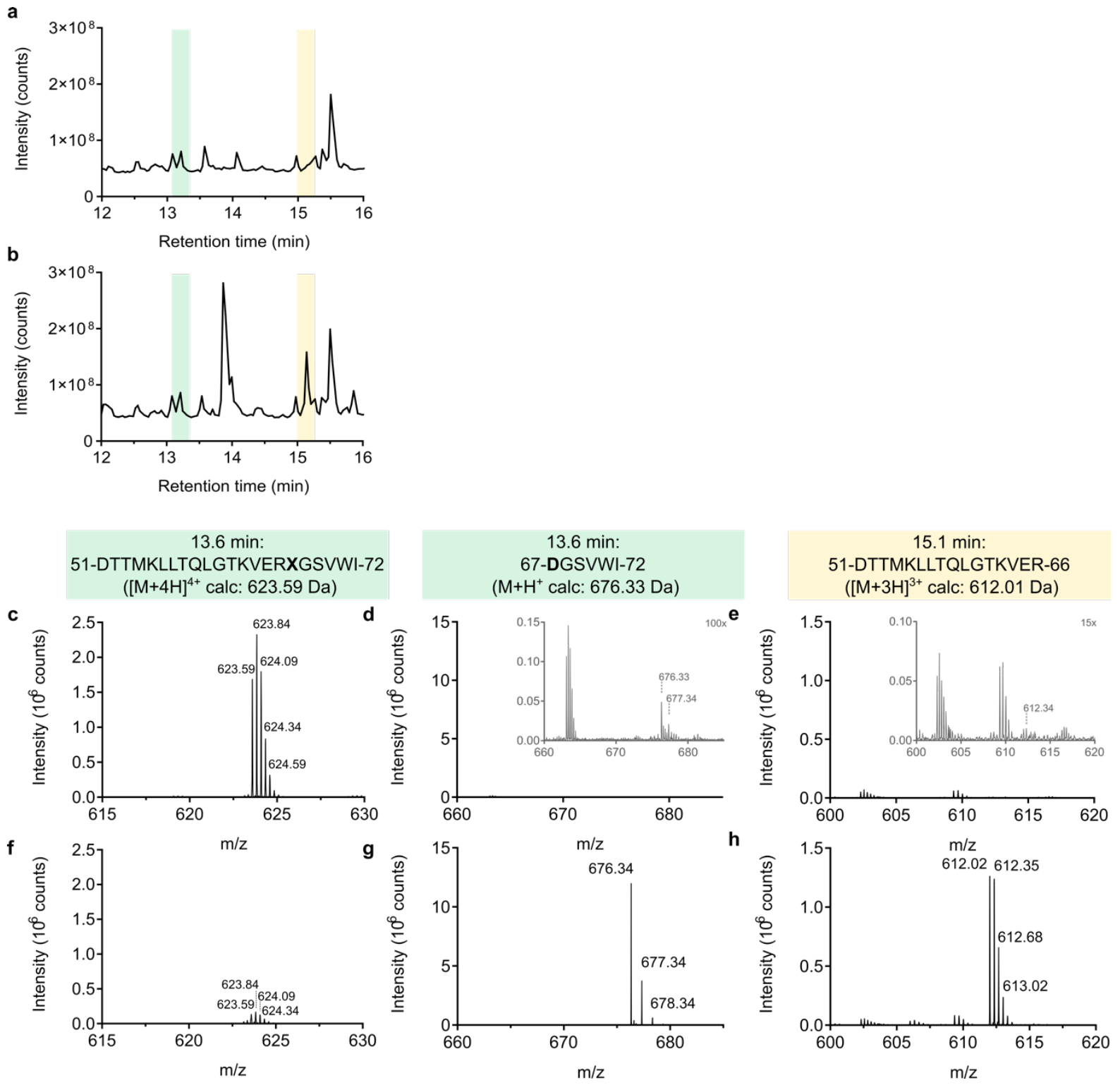

Figure S10: Peptide mapping with Asp-N confirms the modification state of residue 67 in MurA

variants. a-b LC-MS analysis of chromatogram of Asp-N-digested MurA $\mathrm{WWT}_{\mathrm{W}}(\mathbf{a})$ and $\mathrm{MurA}_{\mathrm{N} 67 \mathrm{D}}$ (b). Peaks corresponding to peptides 51-72 (DTTMKLLTQLGTKVERXGSVWI, $13.6 \mathrm{~min}, \mathrm{X}=$ isoAsp), 67-72 (XGSVWI, 13.6 min, X = Asp) and 51-66 (DTTMKLLTQLGTKVER, $15.1 \mathrm{~min}$ ) are shaded in green (13.6 min) and yellow (15.1 min). The total ion count is plotted on the $\mathrm{Y}$-axis. c-e Mass spectra of MurA $A_{W T}$ at retention time $13.6(\mathbf{c}, \mathbf{d})$ and $15.1 \mathrm{~min}(\mathbf{e})$. The observation that position 67 in MurA $\mathrm{W}_{\mathrm{WT}}$ is mostly uncleavable, demonstrates that the majority of MurA $\mathrm{WT}_{\mathrm{T}}$ contains isoAsp. The grey insets in $\mathbf{d}$ and $\mathbf{e}$ are $100 x-$ and $15 x-z o o m s$ of the corresponding mass spectra. $f-h$ Mass spectra of MurA $A_{N 67 D}$ at retention time $13.6(\mathbf{f}, \mathbf{g})$ and $15.1 \mathrm{~min}(\mathbf{h})$. MurA $\mathrm{N} 67 \mathrm{D}_{\mathrm{D}}$ was efficiently cleaved at position 67 , indicating that the mutant predominantly retains L-Asp in this position. 
a
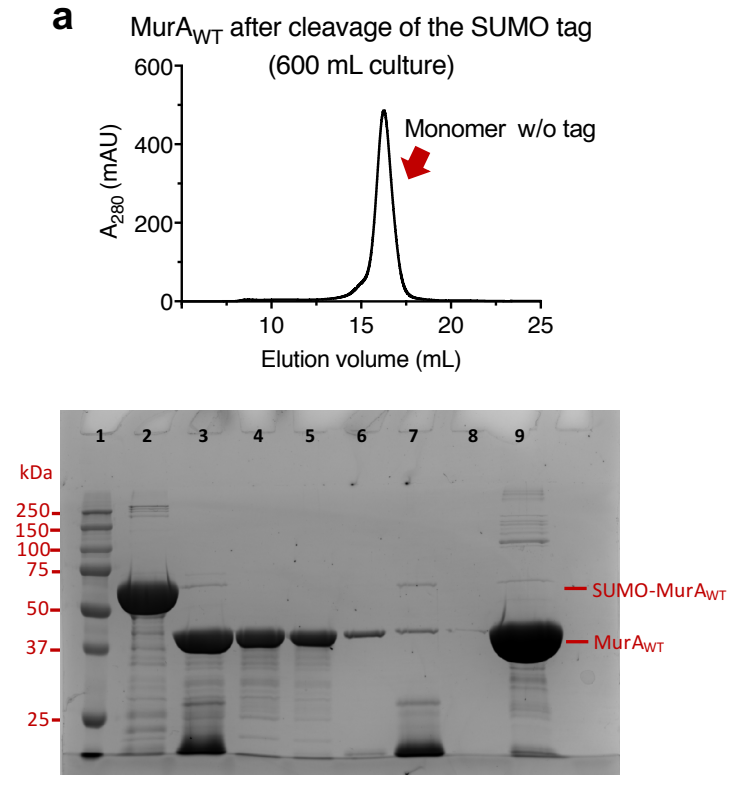

b MurA $_{\mathrm{N} 67 \mathrm{D}}$ after cleavage of the SUMO tag
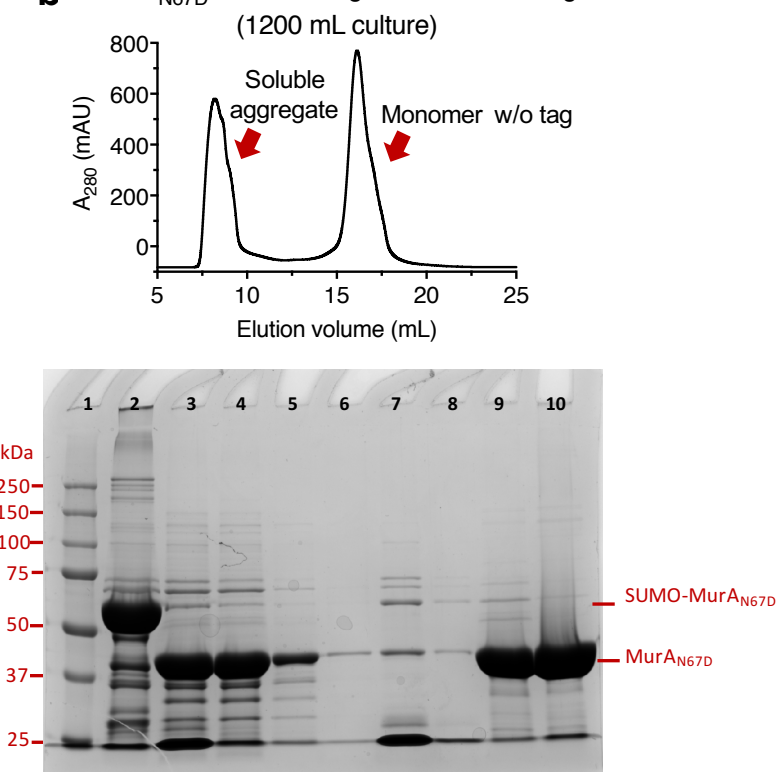

Figure S11: Cleavage of the SUMO tag from MurA variants. Size-exclusion chromatogram (top) and SDS-PAGE analysis of Ulp1 cleavage and purification (bottom) of $\operatorname{MurA}_{W T}(\mathbf{a})$ and $\mathrm{MurA}_{\mathrm{N} 67 \mathrm{D}}$ (b). SUMOMurA $_{W T}$ from a $600 \mathrm{~mL}$ LB culture was used. To obtain sufficient amounts of MurA $A_{N 67 D}$, a $1200 \mathrm{~mL} L B$ culture of SUMO-MurA ${ }_{\text {NG7D }}$ was used. SDS-PAGE Lane 1: protein marker; Lane 2: SUMO-MurA before cleavage; Lane 3: Ulp1 cleavage reaction; Lanes 4-8: Ni-NTA purification with flow through (Lane 4) and washes containing 10, 20, 500, $500 \mathrm{mM}$ imidazole respectively (Lane 5-8). Lane 9, (10): final product after size-exclusion Superdex 200 purification. 
Item name: 200226 TZ200226

Item description: TZ200226 1uM into bufferA

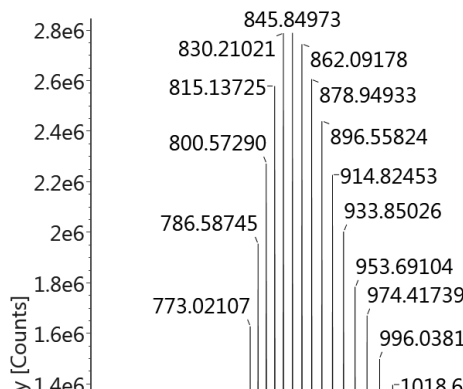

蛋 $1.4 \mathrm{e} 6$

$\stackrel{\text { 巳 }}{\stackrel{c}{\leftrightarrows}} 1.2 \mathrm{e} 6$

$1 \mathrm{e} 6$

$8 \mathrm{e} 5$

$6 e 5$

$4 \mathrm{e} 5$

$2 e 5$

1 1400.31700

700.64001-

$600 \quad 700 \quad 800900100011001200130014001500160017001800190020002100220023002400250026002700280029003000$ Observed mass $[\mathrm{m} / \mathrm{z}]$

Item name: 190807_TZ190805_2

Item description: TZ190805_2 luM

过

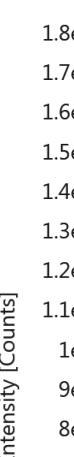

$1.8 \mathrm{e} 6$

$1.6 \mathrm{e} 6$

$1.5 \mathrm{e} 6$

$1.4 \mathrm{e} 6$

$1.3 \mathrm{e} 6$

$1.2 \mathrm{e} 6$

$1.1 \mathrm{e} 6$

$1 e 6$

$9 e 5$
$8 e 5$

$7 e 5$

$6 \mathrm{e}$

$5 e 5$
$4 e 5$
$3 e 5$
$2 e 5$ 100000

815.14755

$800.59459-[\mid[845.83662$

786.56295-

878.98470

773.00808 || |́ 896.52055

$-914.82371$

$-933.84955$

759.92074

747.29195

||||$-1018.66647$

735.04635

Channel name: 1: Average Time 3.2729 min : TOF MS (500-3000) ESI+ : Combined

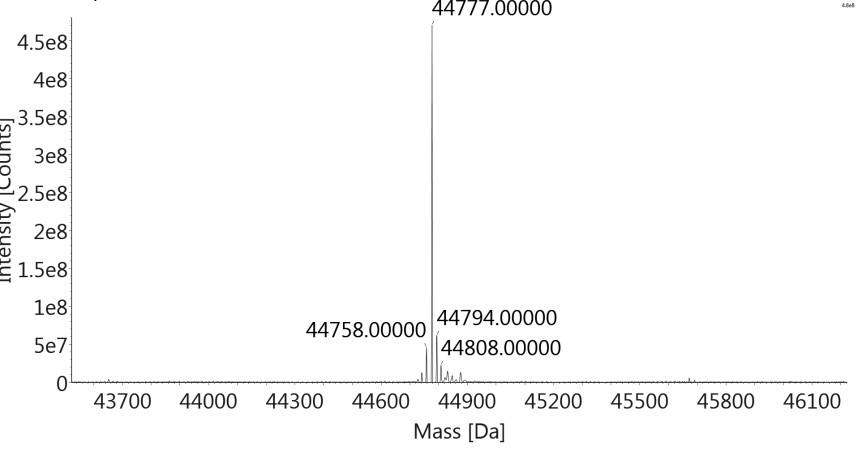

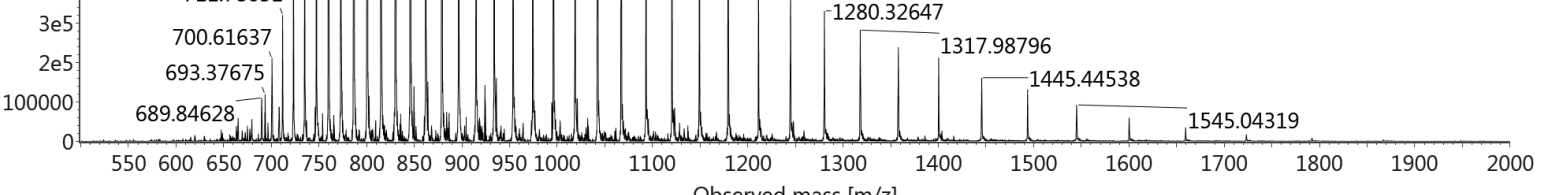

Figure S12: MS analysis of MurA $A_{W T}$ (top, 44777.0 Da observed) and MurA $A_{N 67 D}$ (bottom, 44777.0

Da observed) after tag removal. A mass of $44777.5 \mathrm{Da}$ is expected for both the deamidated MurA $\mathrm{W}_{\mathrm{WT}}$ and $\operatorname{MurA}_{\mathrm{N} 67 \mathrm{D}}$. 
a

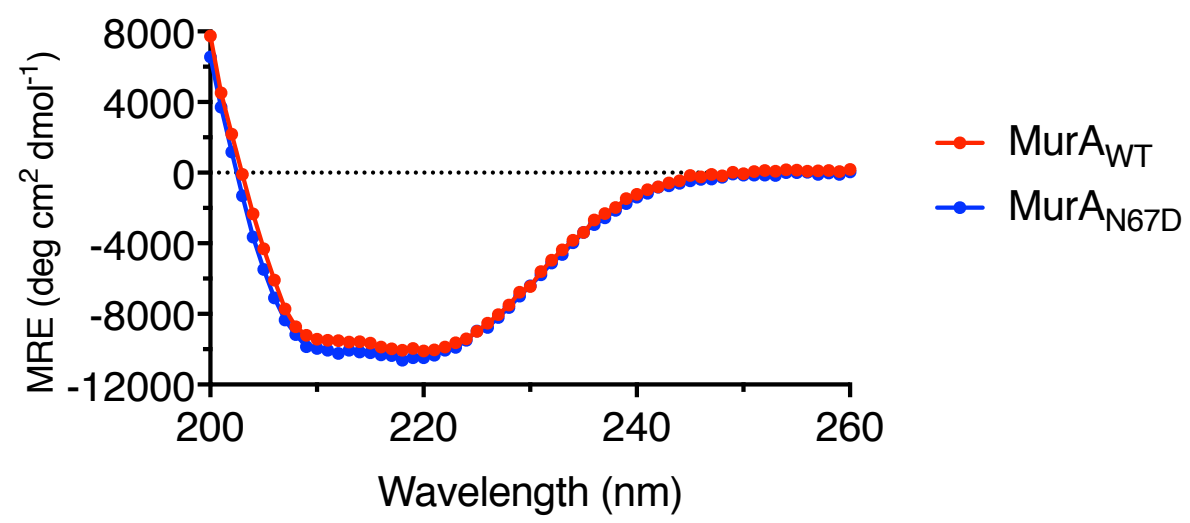

b Collision Cross Section (ion mobility Native MS)

Calculated (based on MurAX-ray structure): 3015 A $^{2}$
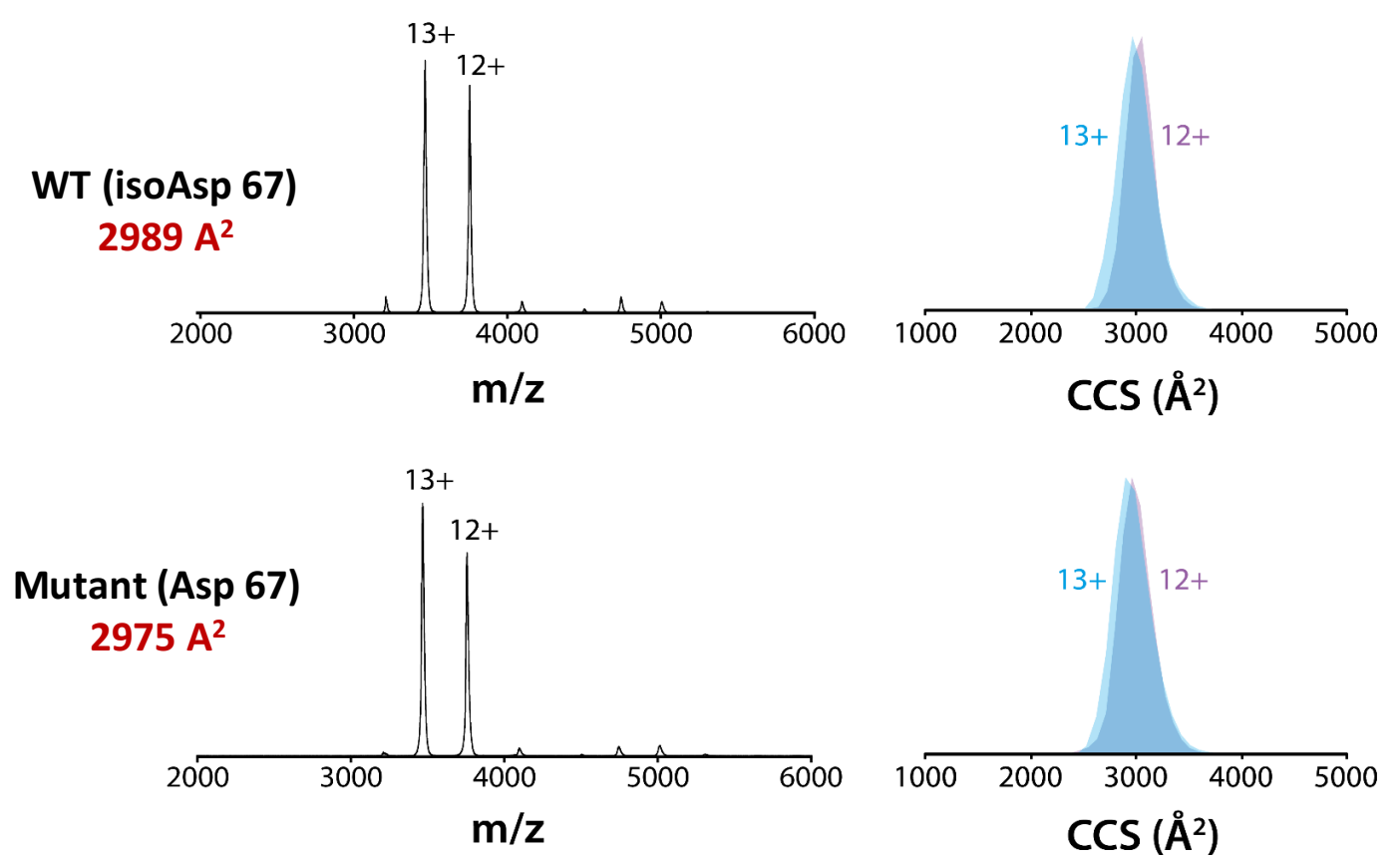

Figure S13: MurA $A_{W T}$ and MurA $A_{N 67 D}$ mutant have similar shape and overall structure. a CD spectra of MurA variants in $10 \mathrm{mM}$ sodium phosphate, $150 \mathrm{mM} \mathrm{NaCl}, \mathrm{pH} 7.6$ at $25^{\circ} \mathrm{C}$. The good overlay of the two $C D$ signatures indicates MurA $\mathrm{WT}_{\mathrm{W}}$ and MurA $_{\mathrm{N} 67 \mathrm{D}}$ have similar secondary structures. $\mathbf{b}$ lon mobility mass spectrometry results of purified active monomer of MurA $A_{W T}$ and MurA $A_{N 67 D}$. Collisional cross section (CCS) is a measurement of protein shape and compactness. The results of MurA $\mathrm{WT}_{\mathrm{WT}}$ and MurA $_{\mathrm{N} 67 \mathrm{D}}$ both match the calculated $\mathrm{CCS}_{\mathrm{PA}}$, suggesting similar global (tertiary) structure. 


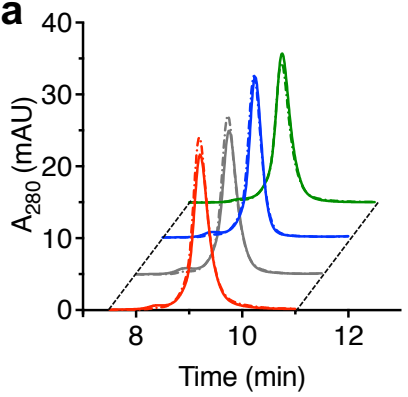

C
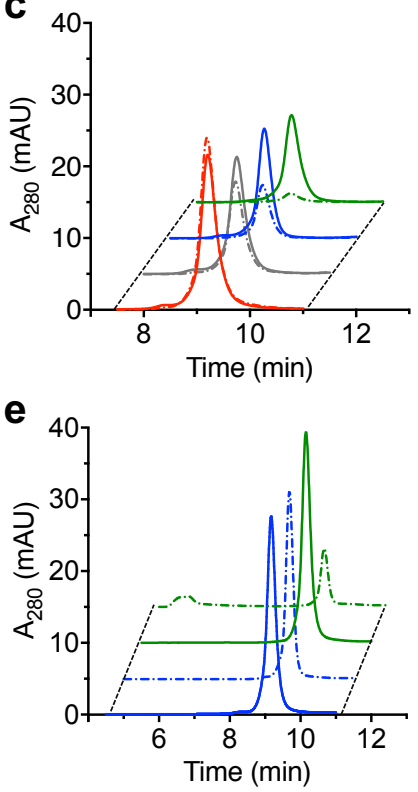

- WT control

- WT $37^{\circ} \mathrm{C}$ heat overnight

-.- N67D $37^{\circ} \mathrm{C}$ heat overnight

- WT $37^{\circ} \mathrm{C}$ low salt

-. N67D $37^{\circ} \mathrm{C}$ low salt

- WT $37^{\circ} \mathrm{C}$ low pH

- N67D $37^{\circ} \mathrm{C}$ low pH

(a)

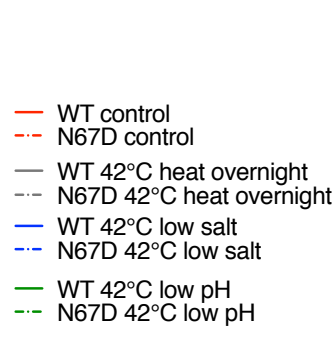

_. $12^{\circ} \mathrm{C}$ low pH

- MurA $\mathrm{WT}_{\mathrm{WT}}$ contro

-.- MurA $A_{W T}$ refolding

- MurA $_{\mathrm{N} 67 \mathrm{D}}$ control

-.- MurA $\mathrm{N}_{\mathrm{N} 67 \mathrm{D}}$ refolding

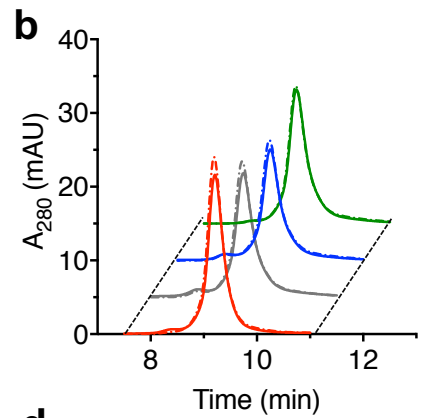

- WT control -. N67D contro

- WT $37^{\circ} \mathrm{C}$ high salt

-. N67D $37^{\circ} \mathrm{C}$ high salt

- WT $42^{\circ} \mathrm{C}$ high salt

- N67D $42^{\circ} \mathrm{C}$ high salt

- WT $47^{\circ} \mathrm{C}$ high salt

-.- N67D $47^{\circ} \mathrm{C}$ high salt

d

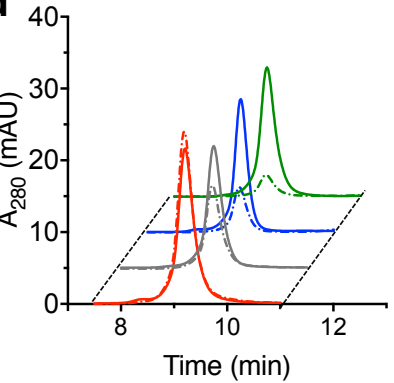

- WT control

-. N67D control

- WT $47^{\circ} \mathrm{C}$ heat $1 \mathrm{~h}$

-.- N67D $47^{\circ} \mathrm{C}$ heat $1 \mathrm{~h}$

- WT $47^{\circ} \mathrm{C}$ low salt

-. N67D $47^{\circ} \mathrm{C}$ low salt

- WT $47^{\circ} \mathrm{C}$ low pH

-.- N67D $47^{\circ} \mathrm{C}$ low pH

Figure S14: Analytical size exclusion chromatograms for in-vitro aggregation experiments. Raw data corresponding to Figure $5 a(a-d)$ and Figure $5 b(e)$. Chromatograms for MurA $A_{W T}$ and MurA $A_{N 67 D}$ are shown as solid and dashed lines, respectively. Monomeric MurA variants are expected to elute at 9.1 min. For clarity, some chromatogram curves are nudged as indicated by dashed lines. 

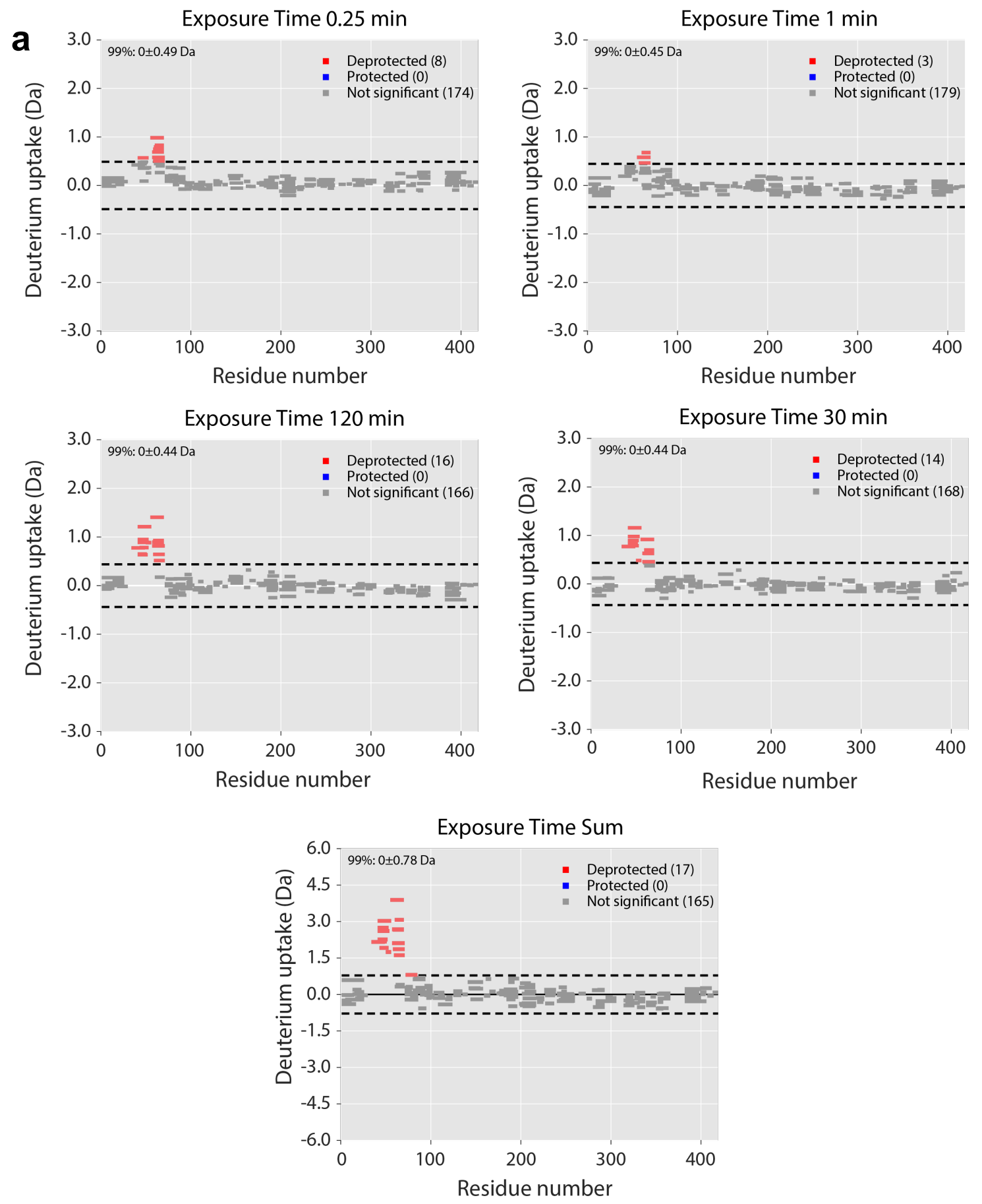

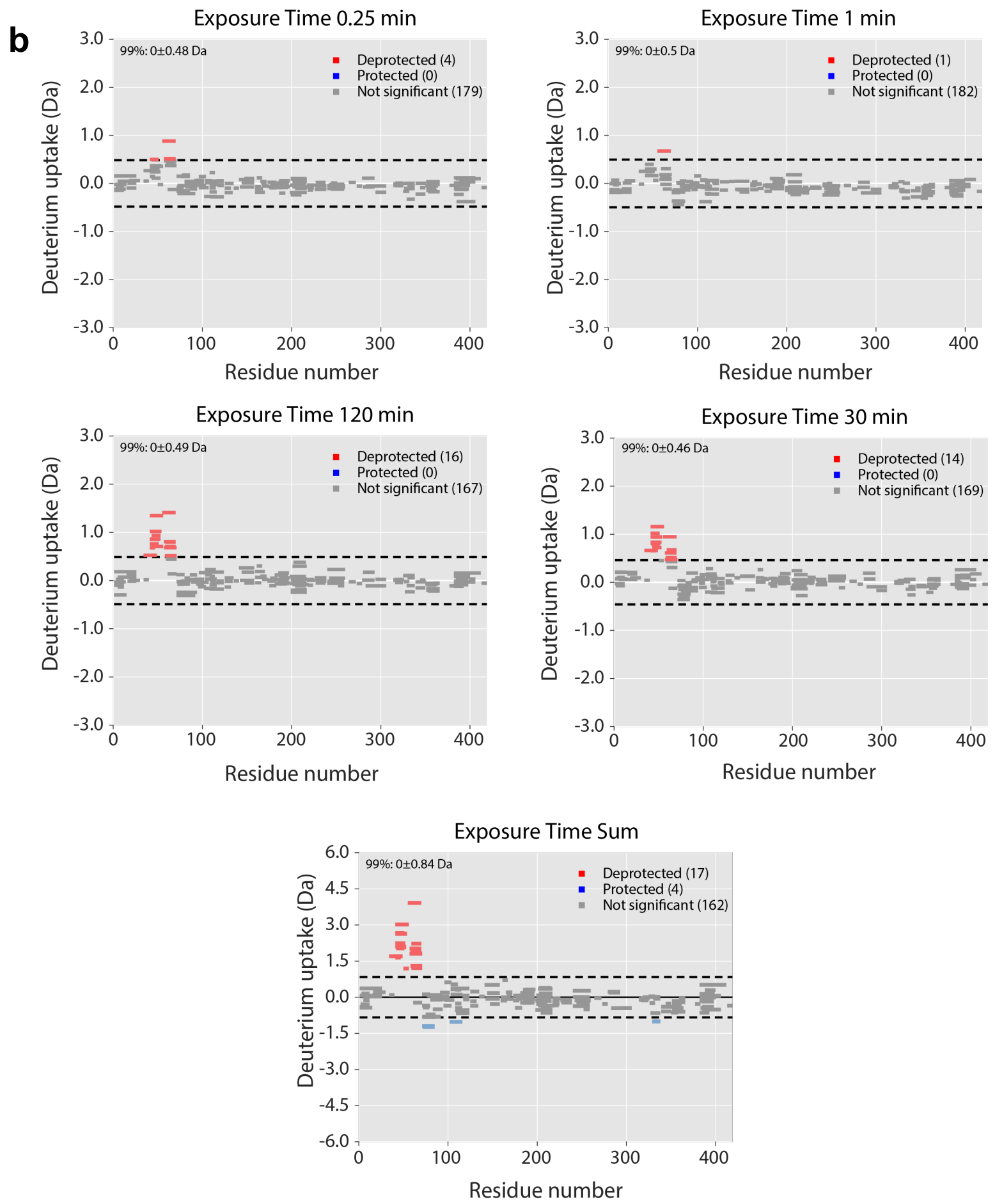

Figure S15: Hydrogen-deuterium exchange Woods-plots which show the difference of deuterium uptake between MurA $A_{W T}$ and MurA $_{N 67 D}$ over a time course of $15 \mathrm{~s}$ to $2 \mathrm{hrs}$. $a$ and $b$ are plots for two biological replicates. 


\section{SUPPLEMENTARY MATERIALS AND METHODS}

All chemicals were purchased from commercial suppliers and used as received without further purification. All solutions were prepared using Milli-Q water (18.2/15.0 $\mathrm{M} \Omega \mathrm{cm})$. Oligonucleotides were custom-synthesized and purified by Integrated DNA Technologies. DNA Sequencing was performed using GENEWIZ SANGER sequencing service. Protein concentrations were determined by nanodrop with extinction coefficients calculated using ExPASy ProtParam³

\section{General Procedure for Reverse-Phase Chromatography}

Analytical reverse-phase high-performance liquid chromatography (RP-HPLC) was performed on an Agilent 1260 Infinity II instrument equipped with a dual wavelength UV-VIS detector using a 300SBC18 4.6x150 column at a constant flow of $1 \mathrm{~mL} / \mathrm{min}$ (for isoquant assay reaction, synthetic peptide analysis) or PLRP-S 4.6x150 column at a constant flow of $1 \mathrm{~mL} / \mathrm{min}$ (for analyzing peptide deamidation reaction at elevated temperatures). Purification of the peptide was performed on an Agilent 1260 Preparative HPLC system using a reversed phase Zorbax 300SB-C18 21.2 x $250 \mathrm{~mm}$ column at a flow rate of $20 \mathrm{~mL} / \mathrm{min}$. The gradients were achieved by a mixture of $\mathrm{H}_{2} \mathrm{O}$ containing $0.1 \%$ TFA (solvent $A$ ) and Acetonitrile containing $0.1 \%$ TFA (solvent B).

\section{General procedure for Mass Spectrometry}

High-resolution mass spectra (HRMS) were recorded on a Waters Xevo G2-XS QTof after separation by reverse phase chromatography on a Waters Acquity UPLC. The proteins were analyzed on Waters Acquity UPLC Protein BEH C4, 300A, 1.7um, 2.1 x 50mm column and the peptides on Waters Acquity UPLC BEH C18, 1.7um, $2.1 \times 50 \mathrm{~mm}$ column, with constant flow of $0.4 \mathrm{~mL} / \mathrm{min}$ using gradient of water containing $0.1 \%$ formic acid (solvent $\mathrm{C}$ ) and acetonitrile containing $0.1 \%$ formic acid (solvent D). Typical gradients are described below.

Gradient protein: $0.5 \mathrm{~min}$ with $5 \% \mathrm{D}$, linear gradient from $5-75 \% \mathrm{D}$ over $0.5-5 \mathrm{~min} ; 40^{\circ} \mathrm{C}$ Gradient peptide: 1 min with 5\% D, linear gradient from 5-60\% D over 1-6 min; $60^{\circ} \mathrm{C}$

Peptide $M S^{E}$ experiments (for synthetic peptide MurA $\mathrm{A}_{63-73}$ and its deamidation products) were carried out with the following settings: Ionization source: ESI, positive mode; Mass range: 100-2000 m/z; 
Analyzer mode: Sensitivity; Low Energy: Collision Energy = 6 V; High Energy: Ramp Collision Energy $=15$ to $35 \mathrm{~V}$; Cone Voltage: $40 \mathrm{~V}$.

\section{Plasmid construction}

The gene encoding un-tagged MurA from E. cloacae in pET-9d was a kind gift from the Schönbrunn lab (Moffitt Cancer Center). MurA was subcloned and furnished with a His ${ }_{6}-\mathrm{SUMO}$ tag via Gibson Assembly. The MurA sequence was amplified by PCR with Q5 High-Fidelity DNA Polymerase using primers MurA-F and $-\mathrm{R}$ (See table S1 for primer sequences and annealing temperatures). The acceptor plasmid was amplified using primers pET15b-SUMO-F and -R and a pET15b-SUMO plasmid template. Gibson assembly of gel-purified fragments was carried out using a 10-fold molar excess of insert with NEBuilder HiFi DNA Assembly Master Mix. The reactions were subsequently transformed into Top10 cells via Heat-Shock and plasmids selected for ampicillin resistance. MurA variants were prepared by site-directed mutagenesis via inverse PCR with Q5 Polymerase (see table S1 for primer sequences). Dpn I, Kinase and Ligase reactions were performed according to the manufacturers instructions (New England Biolabs). Ligation mixtures were transformed into calcium competent E. coli TOP10 cells and selected for ampicillin resistance.

Table S1: PCR Primers used for subcloning. Adapter sequences are indicated in lower case, mutations are underlined.

\begin{tabular}{|c|c|c|c|}
\hline Template & Primer & Sequence (5'-3') & $\mathbf{T a}\left({ }^{\circ} \mathbf{C}\right)$ \\
\hline \multirow{2}{*}{$\begin{array}{l}\text { pET15b- } \\
\text { SUMO- }\end{array}$} & $\mathrm{F}$ & GGATCCGGCTGCTAACAAAG & \multirow[b]{2}{*}{65} \\
\hline & $\mathrm{R}$ & ACCACCAATCTGTTCTCTGTG & \\
\hline \multirow{2}{*}{ MurA- } & $\mathrm{F}$ & acagagaacagattggtggtATGGATAAATTTCGTGTACAGGG & \multirow{2}{*}{63} \\
\hline & $\mathrm{R}$ & ctttgttagcagccggatccTTACTCGCCCTTCACACG & \\
\hline \multirow{2}{*}{ N67D- } & $\mathrm{F}$ & AGTCGAGCGTGATGGCTCCGT & \multirow{2}{*}{68} \\
\hline & $\mathrm{R}$ & TTCGTCCCCAAC̄TGGGTG & \\
\hline \multirow{2}{*}{ R66A- } & $\mathrm{F}$ & GAAAGTCGAGGCTAATGGCTCCGTCTGGATCG & \multirow{2}{*}{65} \\
\hline & $\mathrm{R}$ & GTCCCCAACTG $\overline{G G T G A G C}$ & \\
\hline G68A- & F & GAGCGTAATGCCTCCGTCTGG & 63 \\
\hline
\end{tabular}

\section{Building isoAsp68 in MurA from Vibrio fischerii}

The structure of MurA from Vibrio fischeri (PDB 3vcy) was re-refined using CCP $4^{4}$ by replacing residue 68 (corresponding to residue 67 in E. cloacae) in all four chains with an isoaspartic acid. Refinements were performed iteratively with $\operatorname{Coot}^{5}$ and Refmac $5^{6}$. The Ramachandran plot of the original $3 v \mathrm{vcy}$ structure with Asn68 and the amide torsion angle $\omega$ of the peptide bond between residues 67 and 68 
were calculated using UCSF Chimera ${ }^{2}$. All images of protein structures were generated using UCSF Chimera.

\section{Solid Phase Peptide Synthesis}

Peptides were synthesized on a rink amide resin using microwave assisted Fmoc-SPPS on a Biotage Initiator+ Alstra. Couplings were performed at $70{ }^{\circ} \mathrm{C}$ using DIC/K-Oxyma. Fmoc-deprotection was accomplished with $20 \%$ piperidine in DMF. After the synthesis, peptide $\mathrm{N}$-termini were acetylated with acetic anhydride and DIPEA and subsequently cleaved from the resin by treatment with cleavage cocktail (95\% TFA, 2.5\% triisopropylsilane (TIS), 2.5\% $\mathrm{H}_{2} \mathrm{O}$ ). Peptides were precipitated with cold diethyl ether, dissolved in 50\% B and lyophilized. The lyophilized powder was dissolved in 50\% DMSO and subsequently purified via RP-HPLC prep C18 column with a gradient of $10-70 \%$ B.

\section{MurA $_{63-73}$ peptide analytical methods}

A peptide encompassing MurA residues 63-73 (sequence: Ac-KVERNGSVWID-NH ${ }_{2}$ ) was synthesized as described above.

Analytical data: RP-HPLC Retention time $=13.3 \mathrm{~min}(\mathrm{C} 18$ column, $5 \mathrm{~min}$ 0\% B, 0-70\% B linear gradient over 25 min at RT); Expected Mass: $1342.70 \mathrm{Da}$, Found: $1342.70 \mathrm{Da}$.

\section{IsoAsp Control Peptides}

Control peptides to validate the isoAsp quantification assay were synthesized as described above (sequence: Ac-SDLWKLLPEXNVLSPLPSQA-NH2, where X is either Asp or isoAsp).

Analytical data $(X=$ Asp): RP-HPLC Retention time $=12.6$ min (PLRP-S column, 25-45\% B over 20 $\min$ at $70^{\circ} \mathrm{C}$ ); Expected Mass: 2262.19 Da, Found: 2262.19 Da.

Analytical data $(X=$ isoAsp): RP-HPLC Retention time $=12.2$ min (PLRP-S column, 25-45\% B over 20 min at $70^{\circ} \mathrm{C}$ ); Expected Mass: 2262.19 Da, Found: 2262.19 Da.

\section{Analysis of protein shape by native mass spectrometry and ion mobility}

MurA $_{W T}$ and MurA $A_{\text {N67D }}(15 \mu \mathrm{M})$ were buffer exchanged into $200 \mathrm{mM}$ ammonium acetate $\mathrm{pH} 7.4$ using Micro Bio-Spin columns (Bio-Rad). Transthyretin (TTR), alcohol dehydrogenase (ADH) and concanavalin A (ConA) were also buffer exchanged as above and used as CCS calibrants. A highresolution qTOF mass spectrometer (Synapt G2Si, Waters) containing a commercial TWIMS (T-wave 
ion mobility) cell was used with a nano-ESI source. The mass spectrometer was run in positive polarity and in sensitivity mode. The instrument was calibrated with cesium iodide. Capillaries were produced with a Flaming/Brown P-97 micropipette puller (Sutter Instruments) and coated with Au:Pd (80:20) using a sputter coater (Quorum Q150RS). The following mass spectrometer settings were used: capillary voltage $1.2 \mathrm{kV}$, sample cone $50 \mathrm{~V}$, source temperature $45^{\circ} \mathrm{C}$, trap pressure $2.64 \mathrm{e}^{-2} \mathrm{mbar}$, drift tube pressure 2.65 mbar, TOF pressure $7.80 \mathrm{e}^{-7} \mathrm{mbar}$, IMS wave height $40 \mathrm{~V}, \mathrm{~m} / \mathrm{z}$ range $100-10000$. Nitrogen was used as the ion mobility gas. Drift times were collected at IMS wave velocities of 550, 600 and $640 \mathrm{~ms}^{-1}$. MassLynx V4.2 (Waters Corp. Manchester, UK) and PULSAR (Oxford University, UK) were used to process the data. TTR, ADH and ConA were used to establish a CCS calibration curve $\left(R^{2}=0.99\right)$ for each of the three T-wave velocities. $C C S_{\text {exp }}$ was converted to $C C S_{H e}$ in PULSAR. The final CCS value was calculated from the average value across the 3 IMS wave velocities for the lowest charge state species $(12+)$. 


\section{Supplementary HDX-MS Information}

\begin{tabular}{|l|c|}
\hline Biological Replicate 1 & Wildtype \\
\hline HDX reaction details & $50 \mathrm{mM}$ Tris-HCl, 200 mM NaCl, pH 7.6 \\
\hline HDX time course (min) & \multicolumn{2}{|c|}{$0.25,1,30,120$} \\
\hline \# of Peptides & \multicolumn{2}{|c|}{182} \\
\hline Sequence coverage & \multicolumn{2}{|c|}{$93.3 \%$} \\
\hline $\begin{array}{l}\text { Average peptide length / } \\
\text { Redundancy }\end{array}$ & $11.9 / 5.54$ \\
\hline Replicates (biological or technical) & \multicolumn{2}{|c|}{3 (technical) } \\
\hline Repeatability & 0.0628 (average S.D.) \\
\hline Significant differences in HDX & \multicolumn{2}{|c|}{$99 \% \mathrm{Cl}$} \\
\hline
\end{tabular}

\begin{tabular}{|c|c|c|}
\hline Biological Replicate 2 & Wildtype & Mutant \\
\hline HDX reaction details & \multicolumn{2}{|c|}{$50 \mathrm{mM}$ Tris- $\mathrm{HCl}, 200 \mathrm{mM} \mathrm{NaCl}, \mathrm{pH} 7.6$} \\
\hline HDX time course (min) & \multicolumn{2}{|c|}{$0.25,1,30,120$} \\
\hline \# of Peptides & \multicolumn{2}{|c|}{183} \\
\hline Sequence coverage & \multicolumn{2}{|c|}{$94.5 \%$} \\
\hline $\begin{array}{l}\text { Average peptide length / } \\
\text { Redundancy }\end{array}$ & \multicolumn{2}{|c|}{$12.1 / 5.61$} \\
\hline Replicates (biological or technical) & \multicolumn{2}{|c|}{3 (technical) } \\
\hline Repeatability & 0.0632 (average S.D.) & 0.0712 (average S.D.) \\
\hline Significant differences in HDX & \multicolumn{2}{|c|}{$99 \% \mathrm{Cl}$} \\
\hline
\end{tabular}




\section{SUPPLEMENTARY REFERENCES:}

[1] Bensen, D. C., Rodriguez, S., Nix, J., Cunningham, M. L., and Tari, L. W. (2012) Structure of MurA (UDP-N-acetylglucosamine enolpyruvyl transferase) from Vibrio fischeri in complex with substrate UDP-N-acetylglucosamine and the drug fosfomycin, Acta. Cryst. F. 68, 382-385.

[2] Pettersen, E. F., Goddard, T. D., Huang, C. C., Couch, G. S., Greenblatt, D. M., Meng, E. C., and Ferrin, T. E. (2004) UCSF Chimera--a visualization system for exploratory research and analysis, J. Comput. Chem. 25, 1605-1612.

[3] Wilkins, M. R., Gasteiger, E., Bairoch, A., Sanchez, J. C., Williams, K. L., Appel, R. D., and Hochstrasser, D. F. (1999) Protein identification and analysis tools in the ExPASy server, Methods Mol. Biol. 112, 531-552.

[4] Winn, M. D., Ballard, C. C., Cowtan, K. D., Dodson, E. J., Emsley, P., Evans, P. R., Keegan, R. M., Krissinel, E. B., Leslie, A. G., McCoy, A., McNicholas, S. J., Murshudov, G. N., Pannu, N. S., Potterton, E. A., Powell, H. R., Read, R. J., Vagin, A., and Wilson, K. S. (2011) Overview of the CCP4 suite and current developments, Acta. Crystallogr. D. 67, 235-242.

[5] Emsley, P., Lohkamp, B., Scott, W. G., and Cowtan, K. (2010) Features and development of Coot, Acta. Crystallogr. D. 66, 486-501.

[6] Murshudov, G. N., Skubak, P., Lebedev, A. A., Pannu, N. S., Steiner, R. A., Nicholls, R. A., Winn, M. D., Long, F., and Vagin, A. A. (2011) REFMAC5 for the refinement of macromolecular crystal structures, Acta. Crystallogr. D. 67, 355-367. 